\title{
AS FACES DE D. DINIS: A CONSTRUÇÃO IMAGÉTICA DO SEXTO REI PORTUGUÊS (1279-1325)
}

\author{
THE FACES OF DENIS OF PORTUGAL: THE IMAGECTIC \\ CONSTRUCTION OF THE SIXTH PORTUGUESE KING (1279-1325)
}

\author{
Cleusa Teixeira de SOUSA* \\ Gilberto Cézar de NORONHA**
}

\begin{abstract}
Resumo: A investigação que ora apresentamos visa a analisar os discursos imagéticos e textuais construídos em torno da figura de um rei - D. Dinis -, realçando a ideia de poder que esteve atrelada a essa construção. Para tanto, buscamos perscrutar os símbolos que se destinaram a compor, propagar e sustentar a potencialidade impelida pela incorporação de elementos que justificam e consolidam a imagem que seus idealizadores buscaram erigir. O corpus de análise é constituído pelas obras $A$ fabricação do rei: a construção da imagem pública de Luís XIV, de Peter Burke, Os reis taumaturgos, de Marc Bloch, e Os dois corpos do rei: um estudo sobre teologia política medieval, de Ernst Katorowicz, entre outros escritos literários e historiográficos que nos conduziram no desenvolvimento de reflexões sobre as imagens criadas acerca da figura desse monarca, conforme os interesses daqueles que as delineavam. Nesse sentido, uma das facetas mais exploradas para sustentar e propagar a imagem de um rei num contexto monárquico medieval está atrelada à justiça e à sabedoria. Essas são fatores de alta eficiência quanto a sua capacidade de persuasão coletiva, a qual induz os seus correligionários e a sociedade a considerá-lo único em seu tempo, ao ponto de corroborarem para a criação de uma atmosfera favorável à rememoração de uma boa memória daquele monarca e de seu reinado.
\end{abstract}

Palavras-chave: D. Dinis. Construção Imagética. Portugal. Boa memória. Imaginário político.

Abstract: This paper aims to analyze the imaginary and textual discourses built around the figure of Denis of Portugal, highlighting the idea of power that was tied to this construction. To do so, we seek to clarify the symbols that were intended to compose, propagate and sustain the potential aura impelled by elements that justify and consolidate the image that its creators sought to sustain. The corpus is composed by the translations to Portuguese of The Fabrication of Louis XIV, by Peter Burke, Les Rois Thaumaturges, by Marc Bloch, and, The King's Two Bodies: a study in Mediaeval political theology, by Ernst Katorowicz, among other literary and historiographical writings that have led us to develop reflections on the images created about the figure of this monarch, according to the interests of those who outlined them. In this sense, one of the most explored facets to sustain and propagate the image of a king in a medieval monarchic context is linked to justice and wisdom. These are highly efficient factors of collective persuasion, which induces coreligionists and society to consider him unique in his time to the point of corroborating for the creation of a favorable atmosphere of remembrance of that monarch or governmental leader's a good memory.

Keywords: Denis of Portugal. Imaging Construction. Portugal. Good memory. Political imaginary.

\footnotetext{
" Doutora em História pelo Programa de Pós-Graduação em História da Universidade Federal de Goiás (PPGH/UFG); Pesquisadora do Centro de História da Sociedade e Cultura (CHSC/Universidade de Coimbra, Portugal; professora de História - Secretaria de Educação do Estado de Goiás. E-mail: cleotsou@gmail.com. ORCID Id: https://orcid.org/0000-0001-7252-9438.

** Doutor em História pela Universidade Federal de Uberlândia (UFU); professor do Instituto de História da Universidade Federal de Uberlândia (INHIS/UFU). E-mail: noronha.gilberto@bol.com.br. ORCID iD: https://orcid.org/0000-0002-9985-2697.
} 


\section{Introdução}

As fontes administrativas e legislativas sobre a realeza portuguesa medieval consideravam os reis como enviados de Deus na terra, aos quais cabia o ofício de governar o povo. A esse exemplo verifica-se a citação: "Dom Dinis pela graça de Deus Rei de Portugal e do Algarve a vos saúde" (ANTT, CHANCELARIA, Liv 1, fl. 83). Nesse sentido, interessa-nos ressaltar que as representações podem ser pensadas como esquemas intelectuais capazes de criar figuras construídas por discursos e imagens positivas e relevantes do personagem moldado de acordo com os atributos favoráveis à sua imagem e à recordação de sua memória. Deste modo, nos propomos a analisar a criação imagética de D. Dinis por meio das fontes cronísticas, legislativas e das obras historiográficas e literárias, dada a relevância deste monarca no cenário régio português de seu tempo.

O tema não é novo na historiografia. Pois, pode-se evocar as pesquisas acerca das realezas inglesa, francesa e até castelhana. Podemos agregar ao grupo de pesquisadores da temática nomes como Peter Burke, em A fabricação do rei, o qual trata da construção consciente da figura pública do monarca. Nessa obra, o autor elabora suas investigações acerca da realeza francesa, ressaltando suas análises sobre a figura emblemática da monarquia absolutista europeia, marcada pelo luxo e pelas demonstrações de riqueza. Esse autor buscou distinguir o mito em detrimento da realidade que se construiu em torno da figura pública de Luís XIV.

Citamos, ainda, a obra de Marc Bloch, Os reis taumaturgos, na qual o autor analisa o caráter maravilhoso do toque real, demonstrando como se devia, primeiramente, atentar para a expectativa coletiva do milagre em detrimento ao próprio acontecimento. $\mathrm{O}$ autor realiza uma investigação comparativa sobre o rito francês e inglês, os quais, a priori, se assemelham, uma vez que o primeiro serviu de base para o segundo. O autor aponta, no entanto, que, durante o período de sua existência, os ritos tenham adquirido diferenças significativas e leve em conta as especificidades que popularizaram esses ritos. Deste modo, Bloch delineou indícios de como a crença no poder taumatúrgico se colocou na literatura médica e eclesiástica como uma forma de legitimação do poder régio. Outra preocupação desse autor centrou-se em mostrar que, apesar das tentativas de imitação dos ritos francês e inglês colocadas em prática por outros soberanos europeus, essas investidas foram frustradas, provavelmente, porque não encontraram eco no sistema de valores subjacentes de seus súditos, lembrando-nos da necessária distinção entre o campo do imaginário e o do simbólico (LE GOFF, 1994).

Ademais, estudiosos do tema buscaram reconstituir a história da apropriação conceitual, a partir da análise de uma quantidade gigantesca de manuscritos e fontes documentais do 
período. Ernest Katorowicz, por exemplo, focou na doutrina dos "dois corpos do rei", tese aceita na Inglaterra absolutista do século XVI, derivada de conceitos adotados por teólogos da Idade Média para caracterizar a Igreja ou o próprio Cristo, apontando que o rei não tinha apenas um corpo. Visto que além de seu corpo natural, essencialmente igual ao de qualquer outra pessoa, ostentava também no imaginário da época um corpo místico, que legitimava o seu poder. Os reis taumaturgos, de Marc Bloch, e Os dois corpos do rei, de Ernest Kantorowicz, tornaram-se obras essenciais para o estudo antropológico da História do poder régio e de suas representações no medievo europeu.

Obras como a de Ariel Omar Guiance, em A pietas e a realeza: modelos de poder na Monarquia castelhana medieval, também investigaram o poder da realeza ocidental. Seus escritos traçam análises sobre as virtudes régias a partir do modelo idealizado por Santo Isidoro de Sevilha, cujo objetivo estava em investigar a influência dos conceitos definidos por Isidoro, quais sejam: a piedade e a justiça, atrelados ao poder monárquico castelhano. Levando em consideração que esses conceitos estavam intrinsecamente ligados à política doutrinária que limitava e moderava a conduta régia, consolidando a ideia de que o comportamento do rei definia e justificava o seu poder político.

Dentre os eruditos do tema poder régio medieval, merece destaque, ainda, Adeline Rucquoi em De los reyes que non son taumaturgos: los fundamentos de la realeza en España, estudo em que a autora discute a História Política e realiza uma análise das abordagens relativas ao poder, enfocando, sobretudo, nos fundamentos delineados entre os modelos de realeza medieval (Francesa, Inglesa e Imperium), pautando-se nas obras de Bloch e Kantorowicz. Rucquoi empreende uma abordagem comparativa do caso específico da Península Ibérica em contraponto com a realeza francesa e inglesa. Para tanto, detém-se na análise do poder régio na Espanha e discute o papel atribuído aos ritos e símbolos utilizados pela realeza espanhola. $\mathrm{O}$ argumento que sustenta sua tese assinala que o gesto é formado por um tripé que garante a sua forma, pois é visível, público e ritualizado, consolidando-se como responsável por fundamentar o ato do beija mão. Todavia, é o gesto que confere força ao rito, constituindo uma espécie de poder mágico, sobrenatural que dá forma a esse ato.

Contudo, ao estudar os fundamentos do poder régio na Península Ibérica medieval, é imprescindível conhecer a influência da herança cultural que o Mediterrâneo exerceu sobre a realeza desse período. Enquanto na França e na Inglaterra a afirmação do poder régio se dava através dos gestos, ritos e insígnias, na Espanha, assim como em Portugal, o que consolidava esse poder era a função militar relacionada à assimilação entre a reconquista e a cruzada, uma adoção da sabedoria como um atributo divino próprio dos reis. O gesto que legitimava o poder 
régio na Península Ibérica era o do Beija Mão, por meio do qual demonstrava-se o reconhecimento do poder soberano dos reis. O gesto era compreendido também como uma espécie de submissão que pertencia a um conjunto de gestos específicos da sociedade feudal e que era reservado à nobreza.

Todavia, os gestos fundadores do poder régio da França e da Inglaterra, quais sejam a unção, a consagração, a coroação e os poderes milagrosos, não foram fundamentais para o exercício do poder régio ibérico medieval. Os objetos e os signos externos dessa realeza não adquiriram o caráter sobrenatural ou mágico que as outras sociedades lhes atribuíram. Nesse sentido, não houve necessidade de sacralização da realeza. O principal ofício do rei espanhol e português centrava-se em ser um bom guerreiro e zelar pela paz em seu reino.

Para compreender melhor a situação como os autores descrevem a atuação régia de D. Dinis e, para além dela, devemos ressaltar dois pontos fundamentais: 1) como se deu a construção imagética do monarca na sociedade de seu tempo; 2) como a bibliografia literária tem abordado esta construção imagética. A historiografia tem se referido a D. Dinis como um monarca sábio (FERNANDEZ, 2009) e justo (LOUÇÃO, 2009), um rei legislador (LOUÇÃO, 2003), lavrador (BARBOSA, 2009), trovador (FERNANDEZ, 2009), como foi apontado por literatos. Já os historiadores aludem ao tempo da regência dionisina como um período de "crescimento" desse reino, em contraposição à administração subsequente de D. Afonso IV, a qual passou por momentos de crise geral (OLIVEIRA MARQUES, 1996, p. 161); outra característica atribuída a D. Dinis aponta-o como um rei inovador em aspectos ligados ao território, ao patrimônio régio, à legislação, à justiça, à fiscalidade e à sua governança (OLIVEIRA MARQUES, 1996, p.163), e cronistas como Rui de Pina o enaltecem quanto à sua política diplomática e sua administração eficaz. A crônica, como é sabido, possui a tarefa de enaltecer a vida e os feitos do biografado, para que sua memória se perpetue de forma positiva e modelar para os membros de uma dada sociedade na posteridade. Os discursos empreendidos sobre D. Dinis demonstram que esse rei usava de sua instrução privilegiada para atuar com tato nos diversos âmbitos da sociedade e fortalecer o poder régio, em detrimento de outros poderes, como o dos nobres, em seu governo.

Embora possamos nos deparar com alguns estudos relativos ao tema, no tocante à construção imagética de reis portugueses, essa abordagem ainda carece de novas pesquisas e análises que contribuam para a crítica das transformações ocorridas sob o cetro desse monarca. Deste modo, nossa intenção abarca o propósito de compreender como a historiografia se coloca diante da construção imagética de D. Dinis, o rei que governou Portugal por quarenta e seis anos. Para tanto, ressaltamos que foram vários os cognomes que este monarca recebera, como: 
rei sábio e justo; legislador; lavrador; Pai da Pátria, poeta; civilizador, dentre outros. Contudo, a esse respeito, interrogamos: sob quais bases ou parâmetros fala-se de sabedoria e de justiça real no Portugal do século XIII para que possa ser denominado sábio e justo? Quais eram as intenções e os sentidos da constituição desses dispositivos legais para ser ressaltado como um rei legislador? E, ainda, em relação ao fato de ter recebido o codinome de Pai da Pátria, D. Dinis realmente tinha um projeto de construção de um "Estado Nacional" ou apenas buscava solucionar problemas de sua época?

Dada a especificidade dos documentos acerca da administração régia desenvolvida por esse monarca, percebemos que o desenvolvimento deste trabalho é indissociável de um debate com as diversas manifestações da figura perfeita de um governante, da propaganda política, da construção imagética e historiográfica - discursiva - que projetaram a imagem deste rei vinculada à ideia de um "modelo" de monarca, como se percebe nessa passagem em que se considera que D. Dinis era “dotado de inegáveis dons para o ofício de reinar” (SERRÃO, 1979, p. 247). Observa-se, portanto, que as táticas e as estratégias discursivas são modos privilegiados na construção de figuras de destaque no poder de uma sociedade específica.

O imaginário medieval suscitava nos homens de seu tempo um saber indiciário, constituído pela mentalidade essencialmente simbólica. Como ressalta Santo Agostinho, o mundo constituiu-se por signa (sinais, símbolos) e res (coisas). A representação imagética remete a uma figura idealizada e simbólica. Logo, as narrativas transmitidas, inicialmente, pela oratória e fixadas nos mais distintos suportes, posteriormente, remetem à figura de um monarca ideal. No campo das crônicas, das obras literárias e historiográficas, por vezes seus autores apontam este rei como um modelo de monarca desejável. Conforme descrito "quanto aos seus dotes naturais, D. Dinis foi um modelo de estadista" (SÉRGIO, 1983, p. 23). Tais suportes descritivos sugerem a intencionalidade verbal característica da rememoração de um rei idealizado, muito além da realidade material vivida por D. Dinis na qual se relacionou com os problemas da época e exerceu o seu poder.

Conquanto, buscamos compreender como as elaborações textuais e discursivas possibilitam a elevação de realizações administrativas necessárias em um período, à categoria de grandes feitos. Deste modo, buscamos evidenciar aspectos e elementos textuais, que perpassam esses discursos e compõem eixos de um consenso que pode ser politicamente inferido ou ativado de acordo com os interesses que estão em jogo. Nota-se que esses discursos historiográficos, cronísticos e literários sobre D. Dinis foram sendo elaborados e propagados em diversas temporalidades, criando representações ligadas às virtudes, cujo fito era valorizar a imagem daquele que ocupava o centro do poder. Não foram poucos os que gastaram tinta para 
enfatizar aspectos da vida, da obra e das realizações administrativas e culturais do sexto monarca português D. Dinis (1279-1325), reafirmando diversos cognomes que podem não condizer muito com aquilo que esse monarca fez no século XIII, mas que, certamente, denunciam o que cronistas, historiadores e literatos buscaram fazer dele, desde pelo menos meados do século XVI - El rei lavrador, agricultor, poeta e trovador; Príncipe da Paz (PINTO, 1982), povoador e cultivador de pinos e pinhais (REGO, 1672, p. 17); legislador sábio e justo, Pai da Pátria, Rei Civilizador (FENÁNDEZ, 2009, p.70). Mas, afinal, enunciado por tantos cognomes, quem foi D. Dinis?

D. Dinis nasceu em Lisboa, aos 9 dias do mês de outubro de 1261, e tornou-se, aos dezoito anos de idade, o rei de Portugal. Fazia parte da Dinastia de Borgonha. Filho de D. Afonso III (1247-1279) e da infanta Beatriz de Castela e Gusmão, rainha de Portugal (12531303), D. Dinis era neto de Afonso X (1252-1284), o dito “Sábio", de Castela.

Como é sabido, na época da morte de seu pai, D. Afonso III, em 1279, o reino encontrava-se interditado para a realização de missas e atividades de responsabilidade do poder eclesiástico. O cenário que se delineava em torno do poder monárquico estava conturbado, mediante agudas disputas vividas ao longo do período das guerras civis, especialmente com as tentativas da construção hegemônica da imagem dionisina. $\mathrm{O}$ fato de assumir um reino com problemas relativos ao clero amplia-se na construção de imagens que fornecessem a sustentação ao poder extraordinário de um governante que conseguiu se manter no poder e promover o crescimento econômico e territorial de Portugal. Dessa forma, buscaremos analisar sistematicamente os cognomes recebidos por esse rei.

\section{a) Príncipe da Paz}

Logo no início de seu governo, o reino encontrava-se com os ânimos abalados pelas querelas entre os poderes espiritual e temporal. Seu pai, D. Afonso III (1248-1279), em 1268, tinha sido excomungado pelo arcebispo de Braga e pelos bispos de Porto e Coimbra e pelo papa Clemente IV (1265-1268). O clero havia aprovado um documento que continha quarenta e três denúncias contra D. Afonso III, entre elas encontravam-se o impedimento aos bispos de cobrarem os dízimos, utilização dos fundos destinados à construção dos templos, obrigação dos clérigos de trabalhar nas obras das muralhas, das vilas, prisão e execução de clérigos sem autorização dos bispos, ameaças de morte ao arcebispo e aos bispos e, ainda, a nomeação de judeus para cargos relevantes na coroa. Foi, também, acusado, pelo clero, de apoiar espiritualidades estrangeiras, as quais sejam os franciscanos e os dominicanos. 
O monarca D. Dinis ocupou um lugar ambivalente na relação entre o Estado e a Igreja que oscilou entre a diplomacia na lida com o poder espiritual e a manutenção da ação governamental iniciada por seu pai, visando equilibrar o poder municipal em prejuízo ao clerical e da nobreza. Nos primeiros dez anos de seu governo, este monarca preocupou-se em retirar o reino do interdito papal. Para tanto, escreveu três Concordatas, sendo a primeira composta por 40 artigos; contudo, o poder pontifício exigiu algumas alterações na redação das propostas para atender às solicitações realizadas nas acusações feitas a seu pai. O monarca elaborou, ainda, outras Concordatas inteirando 22 artigos e, por fim, aquela que contabilizava 11 artigos, sendo que, todos eles tinham por objetivo responder às queixas das acusações de abuso régio, em detrimento ao clero.

No decorrer das pesquisas engendradas, percebe-se que D. Dinis foi um rei diplomático, buscando equilibrar os ensejos da Igreja, ao mesmo tempo em que empreendeu uma administração voltada aos seus próprios interesses, de modo a dar continuidade ao reinado que seu pai havia delineado, objetivando alcançar êxito no desenvolvimento econômico, populacional e patrimonial português. Nesse sentido, continuou a ação política de D. Afonso III, que sobrepôs sua autoridade à corte, reduzindo o poder da nobreza, confrontando-se com o poder do clero, centralizando o poder régio em relação aos demais grupos sociais. Essa atuação dos dois reis, para além de sua habilidade política individual, tinha relação com a mudança na configuração política da cristandade no século XIII, o embate da Igreja de Roma com o SacroImpério Romano Germânico. Não por acaso, os reinos e os seus governantes irrompiam como poderes centralizadores particulares em detrimento do universalismo da Igreja (ZLATIC, 2020).

Embora D. Dinis tenha se envolvido na guerra com Castela em 1295, não se manteve nela, desistindo de seus interesses maiores de dominar territórios mais amplos, em troca do recebimento das vilas de Moura e Serpa. Por meio do Tratado de Alcanizes, estabeleceu a paz com Castela em 1297. Esses acordos estabelecidos com o propósito de garantir a paz no reino favoreceram para que este monarca fosse considerado por muitos como o Príncipe da Paz.

\section{b) O Pai da Pátria portuguesa}

Dentre os cognomes pelos quais este rei é recordado, destaca-se a menção de D. Dinis como "Pai-da-Pátria portuguesa" (LEÃO, 1975). A esse respeito, elencamos que suas atividades governamentais foram pautadas em ações necessárias em seu reinado, visto que esse território esteve sob seu governo quando tinha pouco mais de um século de existência como 
reino independente ${ }^{1}$. Dentre as suas principais ações governativas, historiadores destacam o início do processo de constituição ou de identificação nacional ${ }^{2}$ portuguesa, possibilitado a utilização da língua portuguesa, na redação de documentos oficiais lusos, buscando fortalecer o início da formação de uma organização política centralizadora. A esse respeito, percebe-se que houve uma tentativa de enaltecer o reino português como uma "nação"3 em busca de um estado, ainda que incipiente, já no século XIII.

A questão apontada, que lhe confere certa propriedade, está atrelada à unificação da língua (a oficialização do uso da língua portuguesa no aparato régio e nas traduções) por ordem deste monarca. Ainda que seja apressado observar aí o começo do estado nacional, devemos considerar que, como ensinou Max Weber, dentre os vários motivos que conduzem os indivíduos a crer na existência de uma comunhão "nacional", baseada na ação comunitária a base normal dessa motivação está centrada na "comunidade de língua", ou seja, na utilização de uma língua unificada (WEBER, 2009, p. 275).

Ademais, a expansão do patrimônio régio, com a delimitação territorial instituída nas fronteiras com Castela e demais reinos vizinhos, fortalece o argumento da constituição embrionária de uma nacionalidade, na medida em que as fronteiras territoriais são demarcadas, reconhecidas e respeitadas por outros reinos. Um dos aspectos de destaque na historiografia que aborda a administração dionisina é a ação de povoamento das terras lusitanas como um meio de protegê-las de invasões e ataques. Sobre esse mote, cita-se o povoamento de regiões como ocorre na vila de Faro e na Praça dos Tanoeiros, espaços onde o sexto monarca português, em abril de 1315, concedeu aforamentos aos mercadores Rodrigo Eanes e a Galharda de Veneza, garantido esse direito a sua consorte e vizinhos. Contudo, a estratégia régia nessa doação centrou-se em garantir tanto o povoamento dessas terras, como os cuidados com a mesma e garantir que, em troca, seus "proprietários" realizassem benfeitorias nessas localidades. Esse aforamento revela-nos que, dois anos antes do monarca eleger Peçanha como almirante da frota,

\footnotetext{
${ }^{1}$ De acordo com a historiografia vigente, Portugal se tornou um reino independente entre os anos de 1139 e 1143. Quanto a essa data, há controvérsias: os historiadores que consideram 1139 o ano correto consideram como marco o fato de D. Afonso Henriques ter saído vitorioso da Batalha de Ourique contra os Sarracenos. (CINTRA, 1957, p. 168-215; MATTOSO, 1983, p. 13).

${ }^{2}$ Weber menciona que, ao lado das associações políticas, constituídas sobre a base "nacional" no sentido linguístico, está aquela formada por membros da "nação" designada por seu idioma. Contudo, as diferenças de línguas não são obstáculos para o sentimento de comunidade "nacional". Existem, portanto, diversos graus de univocidade qualitativa da crença na comunhão "nacional". A sensação de comunidade de "costumes" e de certos bens comuns da "cultura sensual" é condicionada por rememorações políticas. Como exemplo, estão as relíquias que, para o estranho, são necessárias para despertar o sentimento de "nação" como a bandeira, capacetes militares e de bombeiros com símbolos da pátria (WEBER, 2009, p. 275-277).

${ }^{3} \mathrm{O}$ termo nação vem do latim natio, que designa um povo, ou nação, caracterizado por um conjunto de indivíduos nascidos num mesmo lugar os quais buscam elementos que lhes deem unicidade e lhes identifiquem como parte de um grupo (DICIONÁRIO DE LATIM-PORTUGUÊS, 2001, p. 441).
} 
já havia mercadores venezianos estabelecidos no Algarve. Portanto, a estratégia de D. Dinis se manteve em povoar e resguardar o território herdado de seu avô, Afonso X, anexado ao reino português por medidas dionisinas (MARQUES, 1998).

Outra medida que favoreceu a especulação dos enaltecedores da figura régia de D. Dinis é a ação administrativa, política e cultural de criação da Universidade de Coimbra e os estudos jurídicos no reino. Ou, ainda, sua atuação política na reunião de investimentos "privados" e organização da marinha portuguesa, sob o comando de Manuel Peçanha (SOUSA, 2019). Todos esses aspectos podem ser vislumbrados no estudo de Joaquim Veríssimo Serrão:

[...] a busca de uma fronteira estável que levou a formação de um sentimento nacional, a organização interna, buscando os caminhos da justiça e do fomento; o cuidado posto na organização da marinha e na defesa dos castelos, a rotecção que dispensou à cultura, à religião e à arte, dotando o reino de um Estudo Geral e fundando mosteiros e escolas [...] (SERRÃO, 1979, p. 247-248).

Conforme se torna perceptível, as iniciativas dos autores de associarem as ações político-administrativas adotadas por D. Dinis, no sentido de desenvolver uma política voltada para a criação de uma nação em que se objetivava constituir uma identificação nacional no reino português, trata-se de uma tentativa um pouco forçada de mostrar a modernização incipiente do reino desde os finais do século XIII e início do XIV. Conforme verifica-se nas palavras de Pizarro, “[...] a criação da primeira universidade portuguesa, a nossa Alma Mater, tem também um lugar num quadro político mais vasto, delineado por D. Dinis, foi definido por José Mattoso como uma política de nacionalização, uma política que passou por uma rigorosa delimitação fronteiriça" (PIZARRO, 2012, p. 180) ${ }^{4}$. Contudo, sabe-se que D. Dinis buscou estabelecer uma política favorável ao fortalecimento do poder régio em detrimento ao poder da nobreza e do clero.

Se D. Dinis recebeu o título de "Pai da Pátria" dentre seus biógrafos, historiadores e literatos, é bom lembrar que nesse raciocínio ele também tem uma "mãe". Ou seja, é notória a relevância de Isabel de Aragão, a "Rainha Santa de Portugal", no desenvolvimento da política régia deste monarca. A priori, o casamento entre D. Dinis e Isabel (11 de fevereiro de 1281) representou um ato político de aliança entre Portugal e Castela. Dessa união, foram concebidos 2 filhos, Constança (1290) e Afonso (1291). O último sucedeu o trono de seu pai, ao passo que o monarca teve outros sete filhos bastardos, os quais entregou a Isabel para que cuidasse e

\footnotetext{
4 A propósito dessa interpretação, é José Mattoso quem identifica os primórdios da consciência nacional portuguesa entre 1096 e 1325, desde o condado Portucalense até a morte de D. Dinis. Naturalmente, essa é uma visão do presente sobre o passado que não é fruto de um amadorismo historiográfico, mas denuncia um posicionamento político do pesquisador frente ao seu próprio presente da escrita (MATTOSO, 1985).
} 
educasse. A rainha era uma religiosa fervorosa e mantinha fortes laços com os eclesiásticos locais, buscava ajudar os pobres e era atuante nas atividades relativas à Igreja. Exerceu forte influência na regência de seu consorte, por ser, segundo a cronística, uma mulher paciente, caridosa, apaziguadora e conselheira. Por duas vezes, intercedeu junto ao filho infante D. Afonso, que querelou com o pai numa verdadeira guerra civil contra o rei em 1320 (pela rivalidade com o seu meio irmão D. Afonso Sanches, para quem D. Dinis pretendia entregar o reino). A paz entre os dois foi estabelecida quatro anos depois de batalhas, em 1324, depois da batalha de Alvalade, na expectativa de assegurar a sucessão régia, o infante D. Afonso exigiu que seu irmão bastardo, D. Afonso Sanches, fosse destituído do cargo administrativo que exercia na coroa.

Isabel faleceu em 04 de julho de 1336 e foi sepultada no Mosteiro de Santa Clara-aNova, em Coimbra, onde ela vivia e, mesmo antes, já o sustentava com altas doações. Em 1516, foi beatificada pelo papa Leão X e, em 1625, foi canonizada pelo papa Urbano VIII, tornandose a Rainha Santa Isabel de Portugal (BRANDÃO, 2008).

\section{c) Rei Civilizador: El rei lavrador, agricultor, povoador e cultivador de pinos e pinhais}

Quanto à imagem de rei civilizador, cultivada pelos historiadores preocupados com a formação da nação portuguesa, enfatiza-se que teria sido engajado nas questões pertinentes ao plantio e ao cultivo das terras. D. Dinis tinha especial ligação com o Mosteiro de Alcobaça, onde, estabeleceu amplo convívio e pôde contar com a contribuição dos cistercienses na política agrária que buscou desenvolver fomentando a disseminação do conhecimento das técnicas agrícolas dominadas pelos monges de Alcobaça.

D. Dinis dispensava atenção especial à biblioteca da Abadia cisterciense e, como um homem culto de seu tempo, possivelmente era conhecedor das obras de Xenofonte, de Teofrasto e de Demócrito, as quais tratavam das ciências agrárias; e esse acervo fazia parte do arcabouço intelectual dos monges agrônomos cistercienses deste Mosteiro. Nesse sentido, demonstrava especial interesse em conviver com esses sábios monges especialistas nas ciências e nas técnicas relativas à agricultura; e muito tinham a contribuir com seu empreendimento povoador, visto que o Mosteiro de Alcobaça presenciou o esplendor difundido ao trabalho agropastoril e nos aspectos relativos à vida monástica (VAN BATH, 1975). Pois, de acordo com Georges Duby, a participação dos monges cistercienses na vida rural foi relevante e levaram o avanço técnico mais longe que outras sociedades, para além de terem as melhores juntas e alfaias em suas terras (DUBY, 1980). 
A esse respeito, salienta-se ainda a forma impressionante como aqueles monges povoaram e desenvolveram a agricultura nas terras que lhes foram concedidas. Em menos de um século e meio, de meados do século XIII e primórdios do XIV, ergueram um vasto e opulento domínio que recebeu o nome de "Coutos de Alcobaça”. Esse empreendimento dos cistercienses consiste numa das páginas mais curiosas e brilhantes da história agrária medieval portuguesa, conforme enfatiza Natividade (1929). A própria fundação de mosteiros no período medieval esteve atrelada a um dos meios mais eficazes de povoar lugares desertos, pois em volta das residências monásticas, a população e a cultura ampliavam-se rapidamente (HERCULANO, 1981).

Mesmo antes de D. Dinis assumir o reino, o Mosteiro de Alcobaça já possuía uma Abadia famosa pelo exercício da religiosidade e pela dedicação dos monges aos estudos e aplicação de seus conhecimentos relativos aos alfarrábios às fainas agrícolas, tendo em vista o aperfeiçoamento das técnicas agrícolas e a ampliação da produção. A relevância cultural dos monges cistercienses contribuiu, de sobremaneira, para que D. Dinis empreendesse sua política agrária em Portugal. Tendo em vista o conhecimento elevado que detinham, os cistercienses eram constantemente convidados para aconselharem os reis; noutras ocasiões também exerciam tarefas e missões de cunho político-administrativo em favor do poder régio.

Portanto, quando D. Dinis empreendeu a ação política-administrativa e econômica voltada para a redução da cultura do Paul Ulmar, de Leiria, e para o seu compartilhamento com quem quisesse o lavrar, encarregou o monge de Alcobaça, Fr. Martinho, de algumas tarefas e como seu Esmoler, o qual cumpriu perfeitamente o ofício que lhe fora atribuído, satisfazendo os anseios do rei e dos lavradores do reino (SÃO BOAVENTURA, 1829). A política agrária adotada por D. Dinis se instituiu pela troca de favores com os monges cistercienses. De um lado, o monarca conferia ao mosteiro de Alcobaça e aos monges cistercienses amplos privilégios, ao passo que os monges o assessoravam no desenvolvimento de sua política agrária. Essa ia muito além da política do plantio dos famosos pinheiros e pinhais para conter as grandes ventanias que levavam areia aos espaços despovoados, que, por sua vez, comprometia as terras de plantio concedidas por D. Dinis.

\section{d) Poeta e trovador}

Os historiadores do reino de D. Dinis enfatizam que ele teve uma educação privilegiada. Tendo parte de seus ensinamentos ocorrido na corte de seu avô, Afonso X, D. Dinis tornou-se 
culto ${ }^{5}$ e curioso em relação às letras e às ciências. Há indícios de que foi o primeiro rei português alfabetizado, pois ele foi o único monarca, até seu tempo, a assinar seu nome completo. Instituiu o uso da língua vulgar na escrita e na oralidade em Portugal, pois a língua empregada no ensino era, até então, o latim, embora os textos medievais manuscritos em vernáculo fossem mais usados para serem ouvidos do que propriamente lidos. O português começou a ser escrito a partir do século XIII, sem que as pessoas o estudassem para escrevê-lo, o mais provável é que D. Dinis já "dominasse” a língua portuguesa por conta da educação que recebera confiada aos melhores mestres e que também fora influenciada pelo ensino do francês e pela cultura elevada de seu avô, Afonso X, o Sábio de Castela (BRANDÃO, 2008). Deste modo, impulsionou a tradução de inúmeras obras literárias para o português. Dentre elas constam os $\operatorname{tratados}^{6}$ Las Siete Partidas, ${ }^{7}$ de seu avô, Afonso X, "o Sábio" de Castela. Também compôs poesias e cantigas de amor e de amigo e se destacou como trovador. E, como visto, criou a primeira Universidade portuguesa em 1290, sediada em Coimbra, inaugurando o Studium Generale (carta de 1 de março de 1290), em Portugal.

\section{e) O legislador sábio e justo}

A imagem de sábio e poeta não está descolada de sua imagem de sábio e justo. $\mathrm{O}$ exercício da justiça está entrelaçado ao da sabedoria. Conforme indica José Carlos Fernández, o saber ver favorece a percepção do modo como um governante deve agir. Salientando que a providência está diretamente atrelada à alma prudente e que, para exercer o ofício da justiça, bem como criar sistemas de leis, tornar uma língua comum ao seu povo, realizar a defesa de um território, buscar possibilitar certos aspectos de uma nacionalidade e dinamizar a economia por meio da organização do trabalho, do comércio e da exploração dos recursos naturais, como o fez D. Dinis, possibilita inferir que este monarca teria sido sábio em suas ações e decisões político-administrativas. Observa-se que, em seu reinado:

[...] a organização e dignificação do trabalho, a preocupação pelo cultivo do intelecto, tão intenso como o da terra; o amparo das indústrias, sem esquecer a mineração, que era básica; o desenvolvimento da marinha mercante indispensável à expansão do comércio internacional; a sábia elaboração de leis justas aplicadas com imparcial espírito de justiça; o permanente cuidado de salvaguardar os interesses da plebe, tão

\footnotetext{
${ }^{5}$ A convivência de 17 anos com os conselheiros e nobres figuras de armas da "requintada e mais culta" corte da Europa influenciaram D. Dinis, pois ele aprendeu a admirar os grandes fidalgos e intelectuais que o cercavam, dentre eles o chanceler Estevão Annes (PINTO, 1982).

${ }^{6} \mathrm{D}$. Dinis mandou traduzir algumas obras de Afonso X, as quais o autor não identifica, assim como muitas obras científicas que, no entanto, não são nomeadas (GUINCHO, s/d).

${ }^{7}$ Obra jurídica monumental de Afonso X sistematizou todo o saber jurídico do medievo castelhano, combinando o direito canônico, romano e consuetudinário.
} 
menosprezados pelas classes dominantes na Idade Média, a multiplicação dos concelhos em que os povoados se defendiam melhor da voracidade dos grandes senhores e o constante impulso dado pela instituição da Coroa ao progresso geral do país. (FERNÁNDEZ, 2009, p. 32).

Ao resgatar a memória deste rei, Fernández (2009) buscou enaltecer as ações governamentais desenvolvidas em Portugal sob sua regência, trazendo à tona elementos reais, mas de uma forma enfática e exagerada, ao passo que não é nenhuma novidade visualizar a amplitude das ações administrativas desenvolvidas por D. Dinis. Contudo, faz-se necessário perceber que, naquele momento, muitas dessas ações se tornaram possíveis pelo terreno fértil para o desenvolvimento do reino constituídos por seus predecessores. A esse exemplo, citamos a atuação governamental de seu pai D. Afonso III, que administrou o reino português voltado para iniciativas favoráveis ao seu desenvolvimento social, político e econômico.

D. Dinis é citado pela historiografia como um monarca que se destacou nos aspectos do saber, da justiça e da nobreza:

Fez muitas leis para o bem e regimento da terra e todas sem nenhuma quebra que por
si guardou e mandou inteiramente guardar; por sua grande nobreza foi de todos
celebrado, e lembrado, e por ele muitos Senhores de Nações diversas vinham à sua
Corte pelo ver. Todos os Autores, assi Espanhoes como Estrangeiros, respeitando os
procedimentos deste grande Rey, o celebrão com diferentes elogios (PINA, 1729, p.
287).

A relevância do aparato legislativo no exercício de um bom governo, de acordo com o estudioso da legislação portuguesa Armando Luís de Carvalho Homem, é de essencial relevância. Nesse sentido, afirma que "é pela legislação que o monarca constrói a armadura institucional que sustenta o seu poder" (HOMEM, 1994, p.38). Assinalando que "[...] a legislação do 'lavrador' apresenta, no entanto, suficientes novidades para que a possamos considerar um momento-chave da nossa construção política (HOMEM, 1996, p. 150).

A respeito da justiça portuguesa, é notável salientar que entre agosto de 1280 e novembro de 1322, D. Dinis havia produzido um total de 129 leis, dentre elas 32 não foram datadas. O número de leis promulgadas por este rei, no entanto, foi menor do que aquelas que seu pai, Afonso III outorgou, atos que correspondem a 233 legislações. Contudo, o sexto rei português, se pautou mais nas legislações sobre as questões jurídicas processuais, com aproximadamente 67 leis; 14 delas foram destinadas a querelas sobre dívidas; 10 delas foram destinadas a regulamentar a atividade dos advogados e dos procuradores do reino; 8 foram relativas as apelações e 7 delas versavam sobre agressão. Criou 11 leis sobre a desamortização, 9 sobre o adultério e a moral sexual, 6 sobre os contratos que envolviam judeus e cristãos, 6 
sobre as jurisdições eclesiásticas e eclesiásticos; e delas regulamentaram o ofício do tabelionato (HOMEM, 1994). A produção legislativa deste monarca apresenta dois picos, um entre os anos de 1301-05 e outro entre os anos de 1309 e 1315 (HOMEM, 1994, p. 22), demonstrando que, nesses anos, o monarca desenvolveu ampla reforma processual (CAETANO, 1981, p. 378-79).

Fernández interpreta que suas decisões judiciais são expressão formal e objetiva da sabedoria, demonstrando que a sabedoria e a justiça devem se fazer presentes num corpus legal, que demonstrem a eficácia na administração e nos costumes, os quais foram compilados nas Ordenações Afonsinas. Deste modo, sua "proverbial” justiça o fez ser recordado a partir dessa ênfase “Não há juiz como D. Dinis” (FERNÁNDEZ, 2009, p. 32).

\section{Conclusão}

A amplitude dos repertórios que os estudiosos de D. Dinis desenvolveram sobre o desenvolvimento de suas atividades administrativas demonstram que os autores recorreram a diversas matizes discursivas para a construção das virtudes que um monarca deveria ter e, de seu contrário também, dos vícios que deveriam ser repelidos por um bom representante do poder. A imagem que buscaram construir a seu respeito ressaltou as medidas constitutivas deste governante como o principal centro de poder, aproveitando-se de suas ações positivas para consolidar a figura quase mítica desse rei, vinculado ao imaginário da nação. Lembrando que este monarca criou o Studio Generale em Portugal, oficializou o uso da língua portuguesa dos documentos régios, ordenou a tradução de várias obras do latim para língua vulgar e delimitou o território português facilitando a proteção de seu povo e espaço, foi-lhe conferido o título de "Pai da Pátria". Já a sua ação político-administrativa de favorecimento ao desenvolvimento da agricultura, bem como o povoamento de territórios desabitados, a plantação de pinheiros e pinhais, favorecendo o campo econômico no sentido do aproveitamento de suas madeiras na construção naval e ao mesmo tempo impedido parcialmente que os temporais de areia invadissem as plantações dos lavradores das regiões costeiras. Tais ações são evocadas na enunciação da imagem de rei "lavrador, povoador, civilizador". No entanto, por sua atuação no desenvolvimento do aparato régio legislativo e na execução processual e no âmbito da justiça lusitana, atribuíam-lhe o título de rei "Justo e Sábio". As ações político-administrativas voltadas para proteção do reino e desistência da guerra contra Castela, bem como por suas resoluções, o interdito do reino quanto as questões religiosas, a negociação com o poder eclesiástico resolvendo as querelas entre o poder temporal e o espiritual compõem a imagem de "Príncipe da Paz". 
Eis as imagens instituintes da "fortuna historiográfica" de D. Dinis, para utilizar a expressão de Oliveira Marques ao se referir aos escritos elogiosos de talento de legislador e governante, que elevam sua boa memória e a rememoração das virtudes desde as escritas cronísticas quatrocentistas ou mais tardias, pela historiografia e literatura dos oitocentos ou do primeiro decênio do século XX (OLIVEIRA MARQUES, 1996). Nesse sentido, é válido lembrar que tais imagens e características, elaboradas ou atualizadas por historiadores, mantêm vínculos com projetos historiográficos nacionais. É por esta lente do nacional contemporâneo que revisitam o passado medieval português, desde a seleção das fontes e dos acontecimentos interpretados, quando curiosamente, vale lembrar, não havia clareza de que essa alternativa de "unificação e identificação nacional”, hoje concretizada, seria a vencedora.

Ao revisitar as imagens de D. Dinis que compõem o imaginário político português, compreendemos que não é o passado que nos puxa para trás, mas ele nos empurra é para frente (ARENDT, 2009), para o futuro, o lugar, por definição, da incerteza. Nesse sentido, parece urgente também pensar o projeto historiográfico dos autores que têm exaltado as imagens exemplares de D. Dinis, não para voltarmos ao passado medieval português dos séculos XI ao $\mathrm{XIV}$, mas para considerar as ideias de futuro em jogo quando se exaltam certas características de um governante e não outras. Quais seriam as demandas que impulsionam os autores que enfatizam tais imagens consideradas positivas de D. Dinis? Este nos parece ser tema para um próximo artigo.

\section{Referências}

ANTT, CHANCELARIA DE D. DINIS. Lisboa: Instituto Nacional de Investigação Científica, Liv. I, fl. 83.

ARENDT, Hannah. Entre o futuro e o passado. 6. ed. São Paulo: Perspectiva, 2009.

BARBOSA, Pedro Gomes. El rei-D. Dinis, primeiro de seu nome e $6^{\circ}$ monarca de Portugal. In: FERNANDEZ, José Carlos; LOUÇÃO, Paulo Alexandre (coord.). Dinis, o rei civilizador: uma visão inovadora da vida e obra de um Rei sábio e justo. Lisboa: Ésquilo, 2009.

BLOCH, Marc. Os reis taumaturgos. São Paulo: Companhia das letras, 2018.

BRANDÃO, Frei Francisco. Monarquia lusitana VI. Lisboa: Imprensa Nacional, 2008 [1672].

BURKE, Peter. A fabricação do rei: a construção da imagem pública de Luís XIV. Rio de Janeiro: Jorge Zahar, 1992.

CAETANO, Marcello. História de direito português: fontes direito público (1140-1495). Lisboa: Verbo, 1981. 
CINTRA, Luís Filipe Lindley. Sobre a formação da lenda de Ourique (até a Crônica de 1419). Revista da Faculdade de Letras de Lisboa, n. 23, p. 168-215, 1957.

DICIONÁRIO de Latim - Português. 2. ed. Porto: Porto Editora, 2001.

DUBY, Georges. Guerreiros e camponeses. Lisboa: Editorial Estampa, 1980.

FERNANDEZ, José Carlos; LOUÇÃO, Paulo Alexandre (coord.). Dinis, o rei civilizador: uma visão inovadora da vida e obra de um Rei sábio e justo. Lisboa: Ésquilo, 2009.

FERNANDEZ, José Carlos; LOUÇÃO, Paulo Alexandre. Os Doze Trabalhos de D. Dinis. In: FERNANDEZ, José Carlos; LOUÇÃO, Paulo Alexandre. Dinis: O rei civilizador. Lisboa: Ésquilo, 2009.

FERNANDEZ, José Carlos; LOUÇÃO, Paulo Alexandre. O rei sábio. In. FERNANDEZ, José Carlos; LOUÇÃO, Paulo Alexandre. Dinis: O rei civilizador. Lisboa: Ésquilo, 2009.

GUIANCE, Ariel Omar. A pietas e a realeza: modelos de poder na monarquia castelhana medieval. In. Signum. Revista da ABREM, Associação brasileira de Estudos Medievais, vol. 3, 2001 .

GUINCHO, Maria dos Anjos. História literária e traduções: novos passos de um projecto-ler, escrever, reescrever: O lugar das traduções medievais na historiografia literária. IV Congresso Internacional da Associação Portuguesa de Literatura Comparada. UCP. Disponível em: http://www.eventos.uevora.pt/comparada/VolumeII/LER_ESCREVER_REESCREVER.pdf. Acesso em: set. 2011.

HERCULANO, Alexandre. História de Portugal. Lisboa: Bertrand, 1981.

HOMEM, Luís de Carvalho. “A dinâmica dionisina" e "A corte e o governo central”. In: HOMEM, Luís de Carvalho. Nova história de Portugal. Lisboa: Editorial Presença, 1996.

HOMEM, Luís de Carvalho. Dionisius et Afonsus Dei Gratia Reges et Communis Utilitatis Gratia Legiferi. Separata da Revista da Faculdade de Letras, História, 2ª série, v. XI, Porto, 1994.

KANTOROWICZ, Ernst Hartwig. Os dois corpos do rei. São Paulo: Companhia das Letras, 1998.

LEÃO, Duarte Nunes do. Crónicas dos reis de Portugal: tesouros da Literatura e da História. Porto: Lello \& Irmão Editores, 1975.

LE GOFF, Jacques. O imaginário medieval. Lisboa: Editorial Estampa, 1994.

MARQUES, João Martins da Silva. Descobrimentos portugueses: Documentos para a sua História. Lisboa: Instituto Nacional de Investigação Científica, 1998.

MATTOSO, José. Portugal medieval: novas interpretações. Lisboa: Imprensa Nacional Casa da Moeda, 1983.

MATTOSO, José. Identificação de um país: ensaio sobre as origens de Portugal (1096-1325). v. I - Oposição. V II - composição. Lisboa: Estampa, 1985. 
NATIVIDADE, Joaquim Vieira. Mosteiro de Alcobaça: notas históricas. Coimbra: Imprensa Progresso, 1929.

OLIVEIRA MARQUES, António Henrique Rodrigo de. O poder e o espaço. In: SERRÃO, Joel; OLIVEIRA MARQUES, António Henrique Rodrigo de. Nova história de Portugal. Lisboa: Editorial Presença, 1996.

OLIVEIRA MARQUES, António Henrique Rodrigo de. Portugal na crise dos séculos XIV e XV. Lisboa: Editorial Presença, 1987.

PINA, Rui de. Crônica de D. Dinis. Lisboa: Biblioteca de Clássicos Portugueses, 1899.

PINTO, Américo Cortez. Diónisos: poeta e Rey. Lisboa: Instituto de Cultura e Língua Portuguesa, 1982.

PIZARRO, José Augusto de Sotto Mayor. Reis de Portugal: D. Dinis. Lisboa: Temas e Debates, 2012.

REGO, A. da Silva. Introdução. In: BRANDÃO, Frei Francisco. Monarquia lusitana VI. Lisboa: Imprensa Nacional, 2008 [1672]. p.17.

RUCQUOI, Adeline. De los reyes que non son taumaturgos: los fundamentos de la realeza en España. Relaciones: Estudios de Historia e Sociedad, México, v. 13, n. 51, p. 55-100, 1992.

SÃO BOAVENTURA, Fr. Fortunato de. História chronologica e crítica de real Abadia de Alcobaça. Lisboa: Tipografia da Academia das Ciências, 1829.

SÉRGIO, António. A breve interpretação da história de Portugal. Lisboa: Sá da Costa, 1983.

SOUSA, Cleusa Teixeira. "Entre o Direito Canônico e o Régio: a política diplomática de D. Dinis com os judeus (1279-1325)". In. Atas do XV Simpósio de História Marítima, p. 313-322, 2019.

VAN BATH, Bernard Slicher. História agrária da Europa Ocidental (500-1850). Lisboa: Editorial Presença, 1975.

WEBER, Max. Economia e sociedade: fundamentos da sociologia compreensiva. Brasília: Ed. UnB, 2009.

ZLATIC, Carlos Eduardo. D. Dinis. In: NASCIMENTO, Renata Cristina de Sousa; SOUZA, Guilherme Queiroz de (org.). Dicionário: cem fragmentos biográficos. A idade média em trajetórias. Goiânia: Tempestiva, 2020.

Recebido em: 05/02/2021

Aceito para publicação em: 19/03/2021 